\title{
Neurocognitive Decline in Obstructive Sleep Apnea: An Ignored Entity
}

\author{
Shibdas Chakrabarti ${ }^{1}$, Manas Mengar ${ }^{2}$, Vidushi Rathi ${ }^{3}$, Rohit Kumar $^{4}$, Amit Murar $^{5}$, Pranav Ish $^{6}$
}

\begin{abstract}
Obstructive sleep apnea (OSA) is a common sleep-related breathing disorder causing cognitive dysfunction. Unfortunately, both the disease itself and this disastrous complication go unnoticed due to poor perception for the same. This review attempts to explain the pathophysiology, consequences, and treatment options for the same. The keypoint is early diagnosis and treatment of OSA so as to prevent the cognitive decline. Keywords: Continuous positive airway pressure, Neurocognitive, Obstructive sleep apnea.

Indian Journal of Sleep Medicine (2019): 10.5005/jp-journals-10069-0038
\end{abstract}

\section{INTRODUCTION}

Obstructive sleep apnea (OSA) is a common, yet underdiagnosed sleep-related breathing disorder with significant adverse health consequences. OSA is characterized by a recurrent, functional collapse of the velopharyngeal, and/or, oropharyngeal airway, causing reduced or complete cessation of airflow despite ongoing breathing efforts. This leads to intermittent disturbances in gas exchange (e.g., hypercapnia and hypoxemia) and arousal from sleep, usually at the termination of the apneic episode, resulting in sleep fragmentation and changes in neural activity: all of which are potential mechanisms for the cognitive difficulties that occur in OSA. ${ }^{1}$

Prevalence estimates vary according to the way in which OSA is defined and the distribution of risk factors in the population being studied. The prevalence of sleep disordered breathing (SDB) was $19.5 \%$ and that of obstructive sleep apnoea hypopnoea syndrome (OSAHS) was $7.5 \%$ in healthy urban Indian males between 35 and 65 years of age. ${ }^{2}$ In adults, OSA prevalence rises markedly with age. Between the ages of 30 and 49 years, $10 \%$ of men and $3 \%$ of women are diagnosed, rising to $17 \%$ and $9 \%$, respectively, for $50-70$-yearold. ${ }^{3,4}$ This is critical because the longer OSA goes untreated, the greater the risk of hypertension, ${ }^{5}$ heart disease, ${ }^{6}$ stroke, ${ }^{7}$ kidney disease, ${ }^{8}$ type 2 diabetes mellitus, ${ }^{9}$ and motor vehicle accidents. ${ }^{10}$ The metabolic and vascular consequences, in turn, increase the severity of OSA and the risk of both cognitive impairment and dementia, and potentially bring forward the age of onset of mild cognitive impairment and Alzheimer's disease (AD). ${ }^{11}$

OSA is associated with excessive daytime sleepiness, inattention, and fatigue, which may impair daily function, induce, or exacerbate cognitive deficits, and increase the likelihood of errors and accidents. Systematic and meta-analytic reviews provide robust evidence that OSA impacts neurocognitive functions. Sleep fragmentation or the subsequent daytime sleepiness is among the most important etiologies related to the decline of neurocognitive function in OSA patients. $^{12}$

Continuous positive airway pressure (CPAP) is the most efficacious and widely used medical treatment of OSA, since it improves daytime sleepiness and neurocognitive dysfunction. ${ }^{13}$

To date, the literature on the effect of CPAP on the extent of reversing cognitive deficits, duration of use required for it, and domains of cognition it impacts the most in OSA remains contradictory and sparse
${ }^{1-6}$ Department of Pulmonary, Critical Care and Sleep Medicine, Vardhman Mahavir Medical College and Safdarjung Hospital, New Delhi, India

Corresponding Author: Pranav Ish, Department of Pulmonary, Critical Care and Sleep Medicine, Vardhman Mahavir Medical College and Safdarjung Hospital, New Delhi, India, Phone: +91 9958356000, e-mail: pranavish2512@gmail.com

How to cite this article: Chakrabarti S, Mengar M, et al. Neurocognitive Decline in Obstructive Sleep Apnea: An Ignored Entity. Indian Sleep Med 2019;14(2):38-41.

Source of support: Nil

Conflict of interest: None

\section{ImPACT OF OSA ON COGNITION}

OSA leads to neurocognitive dysfunction which begets OSA like a vicious and never-ending cycle (Fig. 1). Cognitive functions include memory, attention, language, executive function, besides, and visuospatial/constructional abilities. ${ }^{14} \mathrm{~A}$ metaanalysis concluded that all these functions are impacted by OSA. ${ }^{15}$

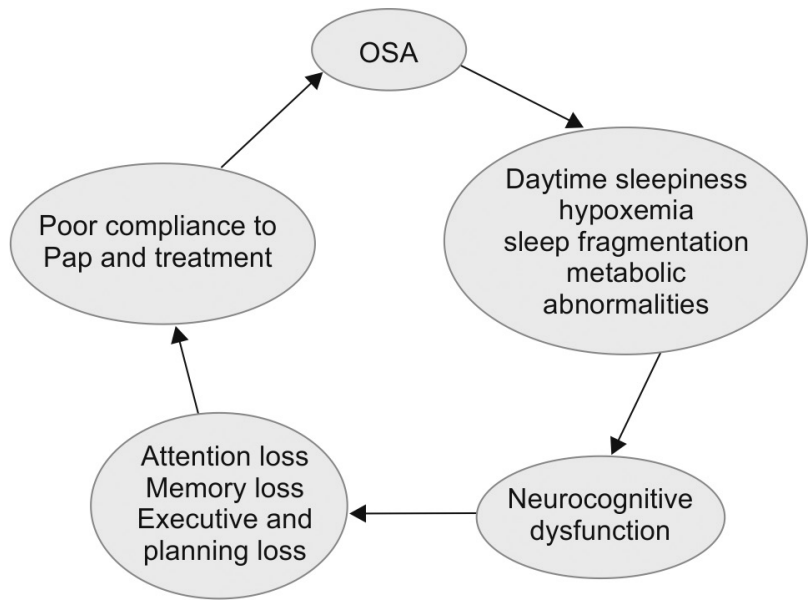

Fig. 1: Vicious cycle of neurocognitive dysfunction in obstructive sleep apnea which can be broken by early diagnosis and appropriate positive airway pressure therapy

(c) The Author(s). 2019 Open Access This article is distributed under the terms of the Creative Commons Attribution 4.0 International License (https://creativecommons. org/licenses/by-nc/4.0/), which permits unrestricted use, distribution, and non-commercial reproduction in any medium, provided you give appropriate credit to the original author(s) and the source, provide a link to the Creative Commons license, and indicate if changes were made. The Creative Commons Public Domain Dedication waiver (http://creativecommons.org/publicdomain/zero/1.0/) applies to the data made available in this article, unless otherwise stated. 
Neurocognitive impairment, ultimately, has an unfavorable effect on patients' productivity at work and social safety and quality of life. ${ }^{16}$

\section{Attention}

It is the most common impaired cognition in OSA. It has been categorized as divided, selective, and sustained attention. ${ }^{17}$ Several studies have demonstrated that drivers with OSA have decreased visual vigilance/sustained attention, which is closely associated with sleep fragmentation/disorder-related daytime sleepiness and tiredness, and they have an increased risk of road traffic accidents. ${ }^{18}$ Studies have also shown that OSA patients have difficulty in involuntary attention switching. ${ }^{19}$ Damage due to loss of attention has a positive association with the OSA severity. ${ }^{20}$

\section{Memory}

OSA is associated with both short-term and working memory deficits, which has been pathophysiologically linked to the hypoxic changes in the hippocampus. ${ }^{21}$ One study suggests that only verbal memory was impaired in OSA patients. ${ }^{22}$ However, there is evidence of visual memory loss also. ${ }^{23}$ A meta-analysis concluded that immediate and delayed recalls, both, were affected in terms of visuospatial and verbal episodic memory. ${ }^{24}$

\section{Executive Functions}

Executive function is as vulnerable to damage as other cognitive functions. This includes loss of fluid reasoning, shifting, and inhibition. A meta-analysis demonstrated that the entire function of planning, working memory, phonological fluency, and cognitive flexibility have been impaired in OSA patients. ${ }^{25}$

\section{Pathophysiology behind Cognitive Dysfunction}

\section{Excessive Sleepiness}

Excessive sleepiness can account for a majority of the neurocognitive deficits in OSA, and its role may even be more than that of hypoxias. ${ }^{26,27}$ Attention deficits may be a result of sleep fragmentation, again, leading to excessive daytime sleepiness. ${ }^{28,29}$

\section{Desaturation}

The old literature documents hypoxia as the principal underlying pathophysiology of cognitive dysfunction. ${ }^{30}$ Hypoxemia may be the trigger for neuronal injury in OSA patients. ${ }^{31}$ In fact, studies have shown that neurocognitive performance correlates with the severity of hypoxemia. ${ }^{32,33}$ Dysfunction of the prefrontal cortex can adversely affect executive functioning. ${ }^{34}$

\section{Sleep Fragmentation}

Sleep fragmentation and daytime sleepiness in OSA influence all the aspects: attention and memory and executive dysfunction. ${ }^{27,34,35}$ An international epidemiological A survey of over 10,000 patients also concluded the same. ${ }^{36}$

\section{Metabolic Factors}

Metabolic disturbance of lipid and protein can contribute to cognitive impairment. ${ }^{16}$ Pediatric OSA with cognitive dysfunction have been found to have a lower concentration of serum insulinlike growth factor (IGF). ${ }^{37}$ Besides, the increased rate of APOE $\varepsilon 4$ allele indicates a hereditary link for neurocognitive impairment in OSA. ${ }^{38}$

\section{EVIDENCE fROM IMAGING}

Advancements in neuroimaging have helped to understand the structural changes in brain structure in cognitive dysfunction. This has recently been also evaluated for OSA patients.

\section{Magnetic Resonance Imaging (MRI)}

Inverse correlation between the ratio of gray matter volume to total brain volume and the visual-fine motor coordination score has been demonstrated using 3D-MRI images of the brain in children. ${ }^{32}$

\section{Functional MRI (FMRI)}

Reduction in brain activation in cingulate, frontal, and parietal regions was found in OSA patients. ${ }^{38}$ Similarly, decreased activation in the prefrontal cortex was found to be associated with impaired executive function. ${ }^{39}$

\section{Magnetic Resonance Spectroscopy (MRS)}

An old study found frontal white matter metabolic abnormalities in OSA patients. ${ }^{40}$ However, lately, focal reductions in frontal gyrus, hippocampus, and parietal cortex have shown correlation with cognitive impairments. ${ }^{41}$

The emerging evidence that gray matter density changes may precede an objective neurocognitive decline in OSA that has trigged a search for markers which can be used in future for screening. ${ }^{42}$ In addition, the response of these changes after CPAP therapy gives rise to the concept of neuroplasticity and the partially reversible features of this neurocognitive dysfunction. ${ }^{41}$

\section{TREATMENT}

CPAP prevents airway collapse, improves respiratory pattern, prevents hypoxia, and corrects sleep fragmentation in OSA. This, in turn, improves daytime sleepiness and neurocognitive dysfunction. The literature supports the response of CPAP for all severities of OSA across all time periods of use in improving excessive daytime sleepiness. ${ }^{43}$

A meta-analysis reported improvement in objective daytime wakefulness [maintenance of wakefulness test (MWT)] with CPAP but no change in objective daytime sleepiness [multiple sleep latency test (MSLT)] in mild OSA. ${ }^{43}$ Several studies have shown that CPAP corrects nocturnal hypoxemia, sleep quality, sleepiness and cognition; the effects being more subjective and higher in severe OSA. ${ }^{44-47}$

CPAP has shown to partly reversed neurocognitive deficits after 3-6 months of use in OSA with excessive daytime sleepiness. The improvement was in attention, vigilance, verbal and visual memory, delayed long-term executive dysfunction, and global cognitive function, but, these were small sample size studies. ${ }^{48-50} \mathrm{~A}$ recent large multicenter trial also reported a transient improvement in frontal-lobe and executive function in severe OSA patients after CPAP. $^{51}$

However, not all the cognitive functions improve with CPAP. A study concluded that while most executive functions improve, short-term memory impairment persists. ${ }^{52}$ Another study demonstrated no dose-response effect of CPAP in the improvement of verbal memory loss. ${ }^{53}$ It has been suggested that this may be due to irreversible chronic hypoxic cerebral damage, particularly in frontal lobes. Besides, the cognitive decline may also be multifactorial and hence, not reversible. ${ }^{53}$

There are very few studies to study the role of CPAP in OSA without daytime sleepiness evaluating the effect of CPAP on OSA patients without EDS. A randomized controlled trial reported 
no benefit in cognitive function (vigilance, memory, attention, information processing) in OSA with the use of CPAP. ${ }^{54}$

\section{Conclusion}

OSA is a common cause of neurocognitive dysfunction which can be best prevented by early diagnosis and institution of therapy in the form of PAP devices. CPAP has even shown to be partly reverse this neurocognitive decline. Hence, a high index of suspicion should be kept for diagnosing neurocognitive dysfunction in all patients of OSA.

\section{References}

1. Edwards BA, Eckert DJ, et al. Obstructive sleep apnoea pathogenesis from mild to severe: is it all the same? Respirology 2016;22:33-42. DOI: 10.1111/resp.12913.

2. Udwadia ZF, Doshi AV, et al. Prevalence of Sleep-disordered Breathing and Sleep Apnea in Middle-aged Urban Indian Men. Am J Respir Crit Care Med 2004;169(2):168-173. DOI: 10.1164/rccm.200302-265OC.

3. Peppard PE, Young T, et al. Increased prevalence of sleep-disordered breathing in adults. Am J Epidemiol 2013;117:1006-10014. DOI: 10.1093/aje/kws342.

4. Reddy EV, Kadhivaran T, et al. Prevalence and risk factors of obstructive sleep apnoea among middle-aged urban Indians: a community based study. Sleep Med 2009;10:913-918. DOI: 10.1016/ j.sleep.2008.08.011.

5. Peppard PE, Young $T$, et al. Prospective study of the association between sleep-disordered breathing and hypertension. N Engl J Med 2000;342:1378-1384. DOI: 10.1056/NEJM200005113421901.

6. Shahar E, Whitney CW, et al. Sleep disordered breathing and cardiovascular disease: cross-sectional results of the Sleep Heart Health Study. Am J Respir Crit Care Med 2001;152:717-720. DOI: 10.1164/ajrccm.163.1.2001008.

7. Arzt M, Young T, et al. Association of sleep-disordered breathing and the occurrence of stroke. Am J Respir Crit Care Med 2005;172: 1447-1451. DOI: 10.1164/rccm.200505-702OC.

8. Gildeh N, Drakatos $\mathrm{P}$, et al. Emerging co-morbidities of obstructive sleep apnea: cognition, kidney disease, and cancer. J Thorac Dis 2016;8:E901-E917. DOI: 10.21037/jtd.2016.09.23.

9. Young T, Peppard PE, et al. Epidemiology of obstructive sleep apnea: a population health perspective. Am J Respir Crit Care Med 2002;165:1217-1239. DOI: 10.1164/rccm.2109080.

10. George CF. Sleep apnea, alertness, and motor vehicle crashes. Am J Respir Crit Care Med 2007;176:954-956. DOI: 10.1164/rccm.200605629PP.

11. Daulatzai MA. Evidence of neurodegeneration in obstructive sleep apnea: relationship between obstructive sleep apnea and cognitive dysfunction in the elderly. J Neurosci Res 2015;93:1778-1794. DOI: 10.1002/jnr.23634.

12. Young $T$, Palta $M$, et al. Burden of sleep apnea: rationale, design, and major findings of the Wisconsin Sleep Cohort study. WMJ 2009;108(5):246-249.

13. Jackson ML, Howard ME, et al. Cognition and daytime functioning in sleep-related breathing disorders. Prog Brain Res 2011;190:53-68. DOI: 10.1016/B978-0-444-53817-8.00003-7.

14. Strauss E, Spreen O. A Compendium of Neuropsychological Tests: Administration, Norms, and Commentary, 3rd ed., Oxford University Press; 2006.

15. Bucks RS, Olaithe $M$, et al. Neurocognitive function in obstructive sleep apnoea: a meta-review. Respirology 2013;18:61-70. DOI: 10.1111/j.1440-1843.2012.02255.x.

16. Grigg-Damberger M, Ralls F. Cognitive dysfunction and obstructive sleep apnea: from cradle to tomb. Curr Opin Pulm Med 2012;18(6): 580-587. DOI: 10.1097/MCP.0b013e328358be18.

17. Gagnon K, Baril AA, et al. Cognitive impairment in obstructive sleep apnea. Pathol Biol (Paris) 2014;62(5):233-240. DOI: 10.1016/ j.patbio.2014.05.015.
18. Karimi M, Hedner J, et al. Attention deficits detected in cognitive tests differentiate between sleep apnea patients with or without a motor vehicle accident. Sleep Med 2015;16(4):528-533. DOI: 10.1016/ j.sleep.2014.11.015.

19. Gosselin N, Mathieu A, et al. Deficits in involuntary attention switching in obstructive sleep apnea syndrome. Neuroscience Letters 2006;408(1):73-78. DOI: 10.1016/j.neulet.2006.08.046.

20. Aloia MS, Arnedt JT, et al. Neuropsychological sequelae of obstructive sleep apnea-hypopnea syndrome: a critical review. J Int Neuropsychol Soc 2004;10(5):772-778. DOI: 10.1017/S1355617704105134.

21. Kloepfer C, Riemann D, et al. Memory before and after sleep in patients with moderate obstructive sleep apnea. J Clin Sleep Med 2009;5(6):540-548.

22. Twigg GL, Papaioannou I, et al. Obstructive sleep apnea syndrome is associated with deficits in verbal but not visual memory. Am J Respir Crit Care Med 2010;182(1):98-103. DOI: 10.1164/rccm.20090100650C.

23. Saunamäki $T$, Jehkonen $M$, et al. Visual dysfunction and computational sleep depth changes in obstructive sleep apnea syndrome. Clinical EEG and Neuroscience 2009;40(3):162-167. DOI: 10.1177/155005940904000308.

24. Wallace A, Bucks RS. Memory and obstructive sleep apnea: a metaanalysis. Sleep 2013;36(2):203-220. DOI: 10.5665/sleep.2374.

25. Olaithe M, Bucks RS. Executive dysfunction in OSA before and after treatment: a meta-analysis. Sleep 2013;36(9):1297-1305. DOI: 10.5665/ sleep.2950.

26. Engleman HM, Kingshott RN, et al. Cognitive function in the sleep apnea/hypopnea syndrome (SAHS). Sleep 2000;23(Suppl 4): S102-S108.

27. Verstraeten E. Neurocognitive effects of obstructive sleep apnea syndrome. Curr Neurol Neurosci Rep 2007;7:161-166. DOI: 10.1007/ s11910-007-0012-8.

28. Ayalon L, Ancoli-Israel S, et al. Relationship between obstructive sleep apnea severity and brain activation during a sustained attention task. Sleep 2009;32(3):373-381. DOI: 10.1093/sleep/32.3.373.

29. Naismith $S$, Winter $V$, et al. Neurobehavioral functioning in obstructive sleep apnea: differential effects of sleep quality, hypoxemia and subjective sleepiness. J Clin Exp Neuropsychol 2004;26(1):43-54. DOI: 10.1076/jcen.26.1.43.23929.

30. Naegele B, Thouvard V, et al. Deficits of cognitive executive functions in patients with sleep apnea syndrome. Sleep 1995;18:43-52.

31. Patil SP, Schneider $\mathrm{H}$, et al. Adult obstructive sleep apnea: pathophysiology and diagnosis. Chest 2007;132:325-337. DOI: 10.1378/chest.07-0040.

32. Quan SF, Chan CS, et al. The association between obstructive sleep apnea and neurocognitive performance-the Apnea Positive Pressure Long-term Efficacy Study (APPLES). Sleep 2011;34:303-314B. DOI: 10.1093/sleep/34.3.303.

33. Bedard MA, Montplaisir J, et al. Obstructive sleep apnea syndrome: pathogenesis of neuropsychological deficits. J Clin Exp Neuropsychol 1991;13:950-964. DOI: 10.1080/01688639108405110.

34. Beebe DW, Gozal D. Obstructive sleep apnea and the prefrontal cortex: towards a comprehensive model linking nocturnal upper airway obstruction to daytime cognitive and behavioral deficits. J Sleep Res 2002;11:1-16. DOI: 10.1046/j.1365-2869.2002.00289.x.

35. Tartar JL, McKenna JT, et al. Sleep fragmentation reduces hippocampal CA1 pyramidal cell excitability and response to adenosine. Neurosci Lett 2010;469:1-5. DOI: 10.1016/j.neulet.2009.11.032.

36. Gall $R$, Isaac $L$, et al. Quality of life in mild obstructive sleep apnea. Sleep 1993;16(8 Suppl):S59-S61. DOI: 10.1093/sleep/16.suppl_8. S59.

37. Ohayon MM, Priest RG, et al. The place of confusional arousals in sleep and mental disorders: findings in a general population sample of 13,057 subjects. J Nerv Ment Dis 2000;188(6):340-348. DOI: 10.1097/00005053-200006000-00004.

38. Ayalon L, Ancoli-Israel S, et al. Relationship between obstructive sleep apnea severity and brain activation during a sustained attention task. Sleep 2009;32:373-381. DOI: 10.1093/sleep/32.3.373. 
39. Thomas RJ, Rosen BR, et al. Functional imaging of working memory in obstructive sleep-disordered breathing. J Appl Physiol (1985) 2005;98:2226-2234. DOI: 10.1152/japplphysiol.01225.2004

40. Kamba M, Inoue $Y$, et al. Cerebral metabolic impairment in patients with obstructive sleep apnoea: an independent association of obstructive sleep apnoea with white matter change. J Neurol Neurosurg Psychiatry 2001;71:334-349. DOI: 10.1136/jnnp.71.3.334.

41. Canessa N, Castronovo V, et al. Obstructive sleep apnea: brain structural changes and neurocognitive function before and after treatment. Am J Respir Crit Care Med 2011;183:1419-1426. DOI: 10.1164/rccm.201005-06930C

42. Yaouhi K, Bertran F, et al. A combined neuropsychological and brain imaging study of obstructive sleep apnea. J Sleep Res 2009;18:36-48. DOI: 10.1111/j.1365-2869.2008.00705.x.

43. Weaver TE, Mancini $C$, et al. Continuous positive airway pressure treatment of sleepy patients with milder obstructive sleep apnea: results of the CPAP Apnea Trial North American Program (CATNAP) randomized clinical trial. Am J Respir Crit Care Med 2012;186:677-683. DOI: $10.1164 / \mathrm{rccm} .201202-02000 \mathrm{C}$

44. Craig SE, Kohler M, et al. Continuous positive airway pressure improves sleepiness but not calculated vascular risk in patients with minimally symptomatic obstructive sleep apnoea: the MOSAIC randomised controlled trial. Thorax 2012;67:1090-1096. DOI: 10.1136/ thoraxjnl-2012-202178.

45. Lau EY, Eskes GA, et al. The role of daytime sleepiness in psychosocial outcomes after treatment for obstructive sleep apnea. Sleep Disord 2013;2013:140725. DOI: 10.1155/2013/140725.

46. Marshall NS, Barnes M, et al. Continuous positive airway pressure reduces daytime sleepiness in mild to moderate obstructive sleep apnoea: a meta-analysis. Thorax 2006;61:430-434. DOI: 10.1136/ thx.2005.050583.
47. Patel SR, White DP, et al. Continuous positive airway pressure therapy for treating sleepiness in a diverse population with obstructive sleep apnea: results of a meta-analysis. Arch Intern Med 2003;163:565-571. DOI: 10.1001/archinte.163.5.565.

48. Castronovo V, Canessa N, et al. Brain activation changes before and after PAP treatment in obstructive sleep apnea. Sleep 2009;32: 1161-1172. DOI: 10.1093/sleep/32.9.1161.

49. Lim W, Bardwell WA, et al. Neuropsychological effects of 2-week continuous positive airway pressure treatment and supplemental oxygen in patients with obstructive sleep apnea: a randomized placebo-controlled study. J Clin Sleep Med 2007;3:380-386.

50. Antic NA, Catcheside P, et al. The effect of CPAP in normalizing daytime sleepiness, quality of life, and neurocognitive function in patients with moderate to severe OSA. Sleep 2011;34:111-119. DOI: 10.1093/sleep/34.1.111.

51. Kushida CA, Nichols DA, et al. Effects of Continuous Positive Airway Pressure on Neurocognitive Function in Obstructive Sleep Apnea Patients: The Apnea Positive Pressure Long-term Efficacy Study (APPLES). Sleep 2012;35:1593-1602. DOI: 10.5665/sleep. 2226.

52. Naegele B, Pepin JL, et al. Cognitive executive dysfunction in patients with obstructive sleep apnea syndrome (OSAS) after CPAP treatment. Sleep 1998;21:392-397. DOI: 10.1093/sleep/21.4.392.

53. Felver-Gant JC, Bruce AS, et al. Working memory in obstructive sleep apnea: construct validity and treatment effects. J Clin Sleep Med 2007;3:589-594.

54. Barbe F, Mayoralas LR, et al. Treatment with continuous positive airway pressure is not effective in patients with sleep apnea but no daytime sleepiness. a randomized, controlled trial. Ann Intern Med 2001;134:1015-1023. DOI: 10.7326/0003-4819-134-11-20010605000007. 